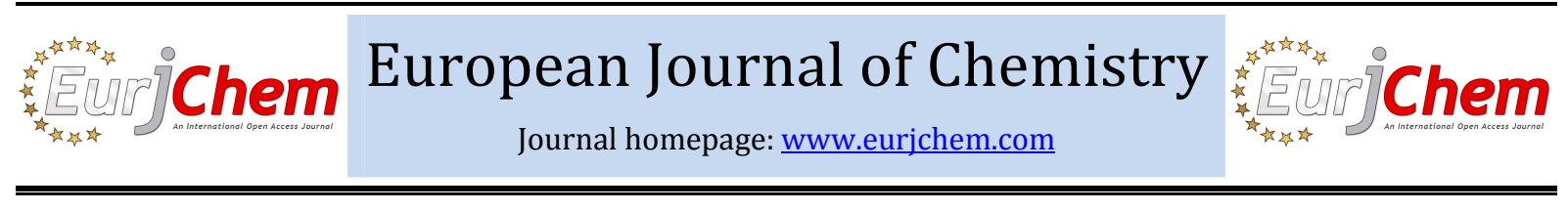

\title{
Crystal structures of racemic and enantiomeric 5-isopropyl-5-methylhydantoin
}

\author{
Masaki Ichitani, Soh-ichi Kitoh, Keiko Tanaka, Shuhei Fujinami, \\ Mitsuhiro Suda, Mitsunori Honda and Ko-Ki Kunimoto * \\ Graduate School of Natural Science and Technology, Kanazawa University, Kakuma-machi, Kanazawa 920-1192, Japan
}

*Corresponding author at: Graduate School of Natural Science and Technology, Kanazawa University, Kakuma-machi, Kanazawa 920-1192, Japan. Tel.: +81.76.2646292. Fax: +81.76.2646292. E-mail address: kunimoto@se.kanazawa-u.ac.jp (K.-K. Kunimoto).

\section{ARTICLE INFORMATION}

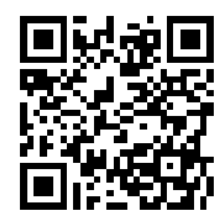

DOI: $10.5155 /$ eurjchem.5.1.6-10.933

Received: 25 September 2013

Accepted: 06 October 2013

Online: 31 March 2014

\section{KEYWORDS}

Hydantoin

Enantiomer

Conglomerate

Crystal structure

Racemic compound

Imidazolidine-2,4-dione

\section{Introduction}

Hydantoins (imidazolidine-2,4-diones) and 2-thiohydantoins (2-thioxoimidazolidin-4-ones) are two classes of 5-membered heterocycles containing two nitrogens in an ureide and a thioureide configuration, respectively. Due to their diverse biological and pharmacological properties, these compounds have been used in a wide variety of applications [1]. For instance, hydantoins have been widely used as antiarrhythmic and antihypertensive [2,3], antiviral [4], antineoplastic [5], antitumoral [6] and anticonvulsant agents [7,8]. Thiohydantoins are known for their uses as hypolipidemic [9], antimutagenic [10] and anticarcinogenic agents [11]. In addition, both compounds are used as herbicides [12] and fungicides agents [13].

These classes of compounds commonly carry the amide and/or the thioamide groups in a molecule, which provides equal number of hydrogen-bond proton donor (D) and acceptor (A) in the D-A-D-A sequence. This unique structural feature endows the compounds with unique physicochemical and biological properties $[14,15]$. We have studied the crystal structures of a series of hydantoins and 2-thiohydantoins in order to get information on the factors controlling the molecular environment in the crystal [16-22].

For a chiral compound, the racemic compound and the enantiomer essentially possess different crystal structures. These differences in crystal structures lead to the different physicochemical properties of the racemic and the enantiomeric compounds. Thus, comparison of the racemic and the enantiomeric crystal structures offers a unique opportunity to study the differences in the intermolecular interactions and the molecular packings involving the same molecule in different crystalline environments.

In this study, the racemate and (S)-enantiomer of 5isopropyl-5-methylhydantoin (( $\mathrm{rac})$-IPrMH) and (S)-IPrMH) have been synthesized (Figure 1). These crystal structures are analyzed by the single crystal X-ray diffraction. Melting temperatures and solid state infrared (IR) spectra of both crystals are also discussed.

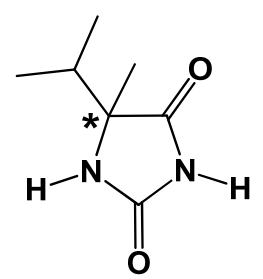

Figure 1. Chemical structure of 5-isopropyl-5-methylhydantoin (IPrMH).

\section{Experimental}

\subsection{Instrumentation}


Table 1. Crystal data and structure refinement

\begin{tabular}{|c|c|c|}
\hline & (rac)-IPrMH & $(S)$-IPrMH \\
\hline Empirical formula & $\mathrm{C}_{7} \mathrm{H}_{12} \mathrm{~N}_{2} \mathrm{O}_{2}$ & $\mathrm{C}_{7} \mathrm{H}_{12} \mathrm{~N}_{2} \mathrm{O}_{2}$ \\
\hline Formula weight & 156.19 & 156.19 \\
\hline Temperature & $123(2) \mathrm{K}$ & $123(2) \mathrm{K}$ \\
\hline Wavelength & $0.71070 \AA$ & $0.71070 \AA$ \\
\hline Crystal system & Monoclinic & Monoclinic \\
\hline Space group & $P 2{ }_{1} / n$ & $P 2_{1}$ \\
\hline \multirow[t]{4}{*}{ Unit cell dimensions } & $a=11.0943(18) \AA$ & $a=6.8048(12) \AA$ \\
\hline & $b=7.1033(11) \AA$ & $b=7.0202(12) \AA$ \\
\hline & $c=11.0940(18) \AA$ & $c=8.8865(16) \AA$ \\
\hline & $\beta=105.636(3)^{\circ}$ & $\beta=90.015(4)^{\circ}$ \\
\hline Volume & $841.9(2) \AA^{3}$ & $424.52(13) \AA^{3}$ \\
\hline$Z$ & 4 & 2 \\
\hline Density (calcd.) & $1.232 \mathrm{~g} / \mathrm{cm}^{3}$ & $1.222 \mathrm{~g} / \mathrm{cm}^{3}$ \\
\hline Absorption coefficient & $0.091 \mathrm{~mm}^{-1}$ & $0.091 \mathrm{~mm}^{-1}$ \\
\hline$F(000)$ & 336 & 168 \\
\hline Crystal size/color & $0.35 \times 0.15 \times 0.08 \mathrm{~mm}^{3} /$ colorless & $0.35 \times 0.15 \times 0.05 \mathrm{~mm}^{3} /$ colorless \\
\hline Theta range for data collection & 3.04 to $27.48^{\circ}$ & 4.76 to $27.42^{\circ}$ \\
\hline \multirow[t]{3}{*}{ Index ranges } & $-14 \leq h \leq 14$ & $-8 \leq h \leq 8$ \\
\hline & $-9 \leq k \leq 9$ & $-9 \leq k \leq 8$ \\
\hline & $-12 \leq l \leq 14$ & $-11 \leq l \leq 11$ \\
\hline Reflections collected & 8776 & 4583 \\
\hline Independent reflections & $1908[R(\mathrm{int})=0.0219]$ & $1028[R(\mathrm{int})=0.0225]$ \\
\hline Completeness & $99.0 \%$ & $98.0 \%$ \\
\hline Absorption correction & Multi-scan [24] & Multi-scan [24] \\
\hline Max. and min. transmission & 0.9927 and 0.9687 & 0.9955 and 0.9690 \\
\hline Refinement method & Full-matrix least-squares on $F^{2}$ & Full-matrix least-squares on $F^{2}$ \\
\hline Data/restraints/parameters & $1908 / 0 / 111$ & $1028 / 1 / 111$ \\
\hline Goodness-of-fit on $F^{2}$ & 1.041 & 1.092 \\
\hline Final $R$ indices $[I>2 \operatorname{sigma}(I)]$ & $R_{1}=0.0437, w R_{2}=0.1174$ & $R_{1}=0.0299, w R_{2}=0.0789$ \\
\hline$R$ indices (all data) & $R_{1}=0.0478, w R_{2}=0.1207$ & $R_{1}=0.0316, w R_{2}=0.0800$ \\
\hline Largest diff. peak and hole & 0.341 and -0.191 e $\AA^{-3}$ & 0.238 and -0.117 e $\AA^{-3}$ \\
\hline Measurement & Rigaku/MSC Mercury CCD diffractometer & Rigaku/MSC Mercury CCD diffractometer \\
\hline Program system & Crystal Structure [27] & Crystal Structure [27] \\
\hline Structure determination & Direct methods (SIR2008 [25]) & Direct methods (SIR2008 [25]) \\
\hline CCDC no & 962338 & 962341 \\
\hline
\end{tabular}

The melting points were measured using a Shimadzu DSC60 differential scanning calorimeter (DSC) equipment. The infrared (IR) spectra were recorded on a Horiba FT-720 Fourier transform infrared spectrometer. IR measurements were carried out by the $\mathrm{KBr}$ method at 64 scans per spectrum with $4 \mathrm{~cm}^{-1}$ resolution. ${ }^{1} \mathrm{H}$ NMR spectra $(500 \mathrm{MHz})$ and ${ }^{13} \mathrm{C}$ NMR spectra (125 MHz) were recorded on a JEOL JNM-ECA 500 spectrometer.

The X-ray diffraction data were collected at 123(2) K by $\omega$ scan technique on a Rigaku/MSC Mercury CCD diffractometer [23] equipped with graphite-monochromatized MoKa radiation $(\lambda=0.71070 \AA)$. The data were corrected for Lorentzpolarization and absorption effects [24]. These structures were solved by direct methods using SIR2008 program [25] and refined by a full-matrix least-squares calculation on $F^{2}$ using SHELXL-97 [26]. All calculations were performed using Crystal Structure software package [27].

The absolute configuration of $(S)$-IPrMH has not been established by anomalous dispersion effects in diffraction measurements on the crystal. The enantiomer has been assigned by reference to an unchanging chiral centre in the synthetic procedure [28]. Non-hydrogen atoms were refined anisotropically. The hydrogen atoms bonded to nitrogen atoms were located in a difference map and refined freely. The remaining hydrogen atoms were positioned geometrically $(\mathrm{C}-\mathrm{H}$ $=0.98$ or $1.00 \AA$ ) and refined using a riding model, with $U_{\text {iso }}(\mathrm{H})$ $=1.2 U_{\mathrm{eq}}(\mathrm{C})$. Structures were visualized using ORTEP-3 for windows [29] and Mercury [30]. Details on data collection and refinement are given in Table 1.

\subsection{Synthesis}

(rac)-5-Isopropyl-5-methylhydantoin was synthesized by slight modification of a literature method [28]. A 1:3 mixture of $\alpha$-methyl- $D L$-valine $(0.20 \mathrm{~g}, 1.53 \mathrm{mmol})$ and urea $(0.27 \mathrm{~g}, 4.57$ mmol) were allowed to react directly in the absence of solvent at $150{ }^{\circ} \mathrm{C}$ for $2 \mathrm{~h}$. This reaction was carried out in a $30 \mathrm{~mL}$ round-bottom flask under stirring using an oil bath as the heat source. After the reaction was complete, water was added while the flask was still warm. The solution was reheated to dissolve all the solids and allowed to cool to room temperature, then placed in a refrigerator for $3 \mathrm{~h}$. The colorless crystals removed by vacuum filtration were further purified by flash column chromatography using hexane and ethyl acetate as eluents. Single crystals suitable for X-ray diffraction were obtained by recrystallization from an aqueous solution.

(S)-5-Isopropyl-5-methylhydantoin was prepared through the reaction of $\alpha$-methyl- $L$-valine $(0.20 \mathrm{~g}, 1.53 \mathrm{mmol}$, Bachem $\mathrm{AG}$, Bubendorf, Switzerland) and urea (0.27 $\mathrm{g}, 4.57 \mathrm{mmol})$ by the same procedure. Single crystals suitable for X-ray diffraction were obtained by recrystallization from an aqueous solution.

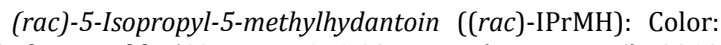
Colorless. Yield: $50 \%$. M.p.: $171^{\circ} \mathrm{C}$. FT-IR (KBr, v, $\left.\mathrm{cm}^{-1}\right): 3218$ $v(\mathrm{NH}), 1765 v(\mathrm{C}=0), 1720 v(\mathrm{C}=0), 1434 v(\mathrm{CN})+\delta(\mathrm{NH}) .{ }^{1} \mathrm{H}$ NMR (500 MHz, Aceton- $\left.d_{6}, \delta, \mathrm{ppm}\right): 0.90\left(\mathrm{~d}, 3 \mathrm{H}, J=6.9 \mathrm{~Hz},\left(\mathrm{CH}_{3}\right)_{2-}\right.$ $\mathrm{CH}), 0.99\left(\mathrm{~d}, 3 \mathrm{H}, \mathrm{J}=6.9 \mathrm{~Hz},\left(\mathrm{CH}_{3}\right)_{2}-\mathrm{CH}\right), 1.38\left(\mathrm{~s}, 3 \mathrm{H}, \mathrm{CH}_{3}-\mathrm{C}\right), 1.97$ (sep, $1 \mathrm{H}, J=6.9 \mathrm{~Hz},\left(\mathrm{CH}_{3}\right)_{2}-\mathrm{CH}$ ), 7.12 (br. s, $1 \mathrm{H}, \mathrm{NH}-\mathrm{CO}-\mathrm{NH}-\mathrm{CO}$ ), 9.58 (br. s, $1 \mathrm{H}, \mathrm{NH}-\mathrm{CO}-\mathrm{NH}-\mathrm{CO}) .{ }^{13} \mathrm{C}$ NMR $\left(125 \mathrm{MHz}\right.$, Aceton- $d_{6}, \delta$, ppm): 178.81 (1C, NH-CO-NH-CO), 157.60 (1C, NH-CO-NH-CO), $66.53\left(1 \mathrm{C}, \mathrm{CH}_{3}-\mathrm{C}\right), 34.95\left(1 \mathrm{C},\left(\mathrm{CH}_{3}\right)_{2}-\mathrm{CH}\right), 22.15\left(1 \mathrm{C}, \mathrm{CH}_{3}-\mathrm{C}\right)$, $17.23\left(1 \mathrm{C},\left(\mathrm{CH}_{3}\right)_{2}-\mathrm{CH}\right), 16.44\left(1 \mathrm{C},\left(\mathrm{CH}_{3}\right)_{2}-\mathrm{CH}\right)$.

(S)-5-Isopropyl-5-methylhydantoin ((S)-IPrMH): Color: Colorless. Yield: 60\%. M.p.: $196^{\circ} \mathrm{C}$. FT-IR (KBr, v, cm-1): 3218 $v(\mathrm{NH}), 1765 v(\mathrm{C}=0), 1720 v(\mathrm{C}=0), 1434 v(\mathrm{CN})+\delta(\mathrm{NH}) .{ }^{1} \mathrm{H}$ NMR $\left(500 \mathrm{MHz}\right.$, Aceton- $\left.d_{6}, \delta, \mathrm{ppm}\right): 0.90\left(\mathrm{~d}, 3 \mathrm{H}, J=6.9 \mathrm{~Hz},\left(\mathrm{CH}_{3}\right)_{2-}\right.$ $\mathrm{CH}), 0.99\left(\mathrm{~d}, 3 \mathrm{H}, \mathrm{J}=6.9 \mathrm{~Hz},\left(\mathrm{CH}_{3}\right)_{2}-\mathrm{CH}\right), 1.37\left(\mathrm{~s}, 3 \mathrm{H}, \mathrm{CH}_{3}-\mathrm{C}\right), 1.97$ (sep, $1 \mathrm{H}, J=6.9 \mathrm{~Hz},\left(\mathrm{CH}_{3}\right)_{2}-\mathrm{CH}$ ), 7.07 (br. s, $1 \mathrm{H}, \mathrm{NH}-\mathrm{CO}-\mathrm{NH}-\mathrm{CO}$ ), 9.54 (br. s, $1 \mathrm{H}, \mathrm{NH}-\mathrm{CO}-\mathrm{N} H$-CO). ${ }^{13} \mathrm{C}$ NMR $\left(125 \mathrm{MHz}\right.$, Aceton- $d_{6}, \delta$, ppm): 178.80 (1C, NH-CO-NH-CO), 157.43 (1C, NH-CO-NH-CO), $66.51\left(1 \mathrm{C}, \mathrm{CH}_{3}-\mathrm{C}\right), 34.97\left(1 \mathrm{C},\left(\mathrm{CH}_{3}\right)_{2}-\mathrm{CH}\right), 22.19\left(1 \mathrm{C}, \mathrm{CH}_{3}-\mathrm{C}\right)$, $17.25\left(1 \mathrm{C},\left(\mathrm{CH}_{3}\right)_{2}-\mathrm{CH}\right), 16.46\left(1 \mathrm{C},\left(\mathrm{CH}_{3}\right)_{2}-\mathrm{CH}\right)$. 


\section{Results and discussion}

(rac)-IPrMH and (S)-IPrMH were synthesized by one-pot reaction of $\alpha$-methyl- $D L$-valine and $\alpha$-methyl- $L$-valine with urea, respectively, in the absence of solvent. (S)-IPrMH was obtained in an optical pure form without racemization in the present reaction condition.

Table 2 and Figure 2 summarize the melting points and solid state IR spectra of IPrMH. (rac)-IPrMH crystal shows a melting point of $171^{\circ} \mathrm{C}$, while $(S)$-IPrMH melts at $196^{\circ} \mathrm{C}$. Thus, the racemic crystal of IPrMH has a lower melting temperature than the enantiopure crystal by $25^{\circ} \mathrm{C}$. As given in Figure 2, the IR spectrum of (rac)-IPrMH is identical with that of the pure enantiomer.

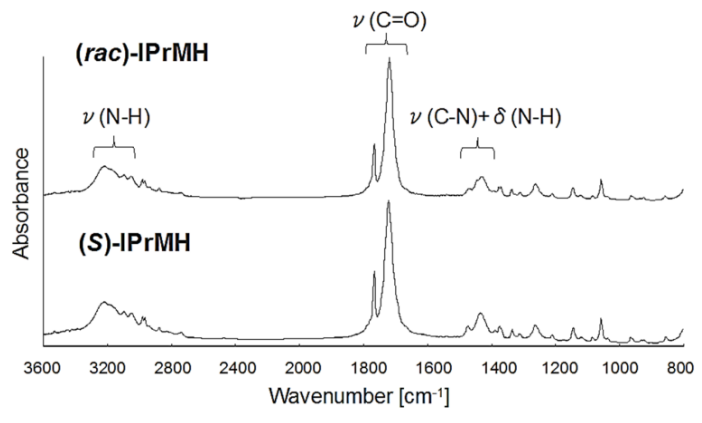

Figure 2. Solid state IR spectra of (rac)-IPrMH and (S)-IPrMH.

Table 2. Melting points and solid state IR spectra.

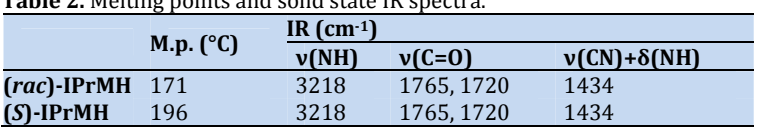

When a racemate crystallizes as a conglomerate (equimolar mechanical mixtures of two crystalline enantiomers), the melting point of the conglomerate is always lower than that of the pure enantiomer, and the solid state IR spectra of the conglomerate are identical with those of the pure enantiomer [31]. On the other hand, the melting point of a racemic compound (equimolar enantiomers are present in the crystal lattice) is generally higher than that of the pure enantiomer, and the solid state IR spectra of the racemic compound are not identical with those of the pure enantiomer [32].

In the present case, the melting point values and the IR spectra suggest the conglomerate formation for the racemic IPrMH crystals. However, the single crystal X-ray diffraction data has shown that the racemic IPrMH doesn't crystallize as a conglomerate but as a racemic compound. Thus, this study presents the rare case of lower melting racemic and higher melting enantiomeric crystals.

Table 1 shows the crystallographic data. Figure 3 and 4 show the molecular structure and atom-labeling scheme of $($ rac)-IPrMH and $(S)$-IPrMH, respectively. Table 3 summarizes the selected geometric parameters. Figure 5, 6 and 7, 8 show the crystal packing of ( $\mathrm{rac}$ )-IPrMH and (S)-IPrMH, respectively. Table 4 shows the hydrogen-bond geometry. As given in Table 1, (rac)-IPrMH crystallizes in the monoclinic system with space group $P 2_{1} / n$ and four molecules in a unit cell. (S)-IPrMH crystallizes in the monoclinic system with space group $P 2{ }_{1}$ and two molecules in a unit cell.

As given in Figure 3, 4 and Table 3, (rac)-IPrMH and $(S)$ IPrMH are very similar in molecular geometries. The hydantoin moieties (N1/C1/01/N2/C2/02/C3) for ( rac)-IPrMH and (S)IPrMH are nearly planar, with maximum deviations of $0.0285(13) \AA$ in N2 and 0.0467(17) $\AA$ in N2, respectively. The orientations of the isopropyl groups, defined by the C5, C6 and
C7 atoms, relative to these planes are given by the torsion angles N1-C3-C5-C6 of 63.46(14) ${ }^{\circ}$ for ( $\mathrm{rac}$ )-IPrMH and $62.8(2)^{\circ}$ for $(S)$-IPrMH. The N1-C1 distances [1.3348(14) Å for (rac)-IPrMH; 1.332(2) A for (S)-IPrMH] are shorter than the N2-C1 distances [1.3818(14) Å for (rac)-IPrMH; 1.384(2) Å for (S)-IPrMH], and the 01-C1-N1 angles [127.31(10) ${ }^{\circ}$ for $(\mathrm{rac})$ IPrMH; $127.67(17){ }^{\circ}$ for $(S)$-IPrMH] are greater than the 01-C1-N2 angles [124.35(10) ${ }^{\circ}$ for (rac)-IPrMH; 124.06(17) ${ }^{\circ}$ for $(S)$-IPrMH].

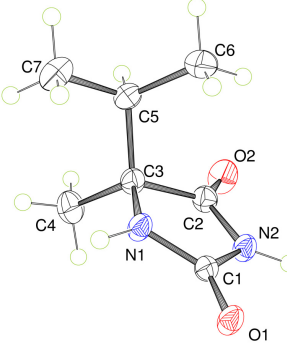

Figure 3. Molecular structure of ( $\mathrm{rac}$ )-IPrMH. Anisotropic displacement ellipsoids are drawn at the $50 \%$ probability level.

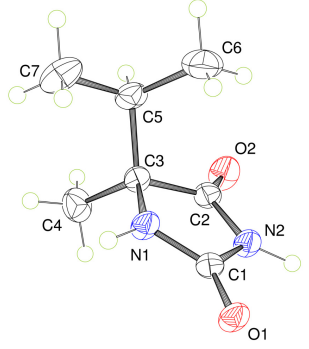

Figure 4. Molecular structure of $(S)-I P r M H$. Anisotropic displacement ellipsoids are drawn at the $50 \%$ probability level.

Table 3. Selected geometric parameters $\left(\AA{ }^{\circ}\right)^{\circ}$.

\begin{tabular}{lll} 
Table 3. Selected geometric parameters $\left(\mathrm{A},{ }^{\circ}\right)$ & \\
\hline Geometric parameters & (rac) -IPrMH & (S)-IPrMH \\
Oond lengths & & \\
O2-C2 & $1.2379(14)$ & $1.2376(18)$ \\
N1-C1 & $1.2084(15)$ & $1.202(2)$ \\
N1-C3 & $1.3348(14)$ & $1.332(2)$ \\
N2-C1 & $1.4652(14)$ & $1.4638(19)$ \\
N2-C2 & $1.3818(14)$ & $1.384(2)$ \\
C2-C3 & $1.3751(15)$ & $1.381(2)$ \\
Bond angles & $1.5366(17)$ & $1.536(2)$ \\
C1-N1-C3 & & \\
C1-N2-C2 & $112.83(9)$ & $113.03(15)$ \\
O1-C1-N1 & $111.55(10)$ & $111.42(14)$ \\
O1-C1-N2 & $127.31(10)$ & $127.67(17)$ \\
N1-C1-N2 & $124.35(10)$ & $124.06(17)$ \\
O2-C2-N2 & $108.34(10)$ & $108.27(12)$ \\
O2-C2-C3 & $126.21(11)$ & $126.08(16)$ \\
N2-C2-C3 & $127.02(11)$ & $127.32(15)$ \\
N1-C3-C2 & $106.77(9)$ & $106.60(14)$ \\
\hline Torsion angles & $100.44(8)$ & $100.55(13)$ \\
N1-C3-C5-C6 & & \\
N1-C3-C5-C7 & $63.46(14)$ & $62.8(2)$ \\
C2-C3-C5-C6 & $-60.23(13)$ & $-61.22(18)$ \\
C2-C3-C5-C7 & $-47.44(14)$ & $-48.4(2)$ \\
C4-C3-C5-C6 & $-171.14(10)$ & $-172.46(14)$ \\
C4-C3-C5-C7 & $-169.84(12)$ & $-170.46(19)$ \\
\hline
\end{tabular}

In (rac)-IPrMH crystal (Figure 5, 6 and Table 4), the amide $\mathrm{N} 1-\mathrm{H}$ and $\mathrm{N} 2-\mathrm{H}$ of one molecule are hydrogen-bonded to the amide 01=C1 groups of neighboring molecules to form $R^{2}{ }_{2}(8)$

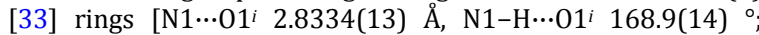
$\mathrm{N} 2 \cdots 01^{i i} 2.8226(13) \AA$, $\mathrm{N} 2-\mathrm{H} \cdots 01^{i i} 168.9(16){ }^{\circ}$; symmetry codes: $($ i) $-x+1 / 2, y-1 / 2,-z+3 / 2$; (ii) $-x+1 / 2, y+1 / 2,-z+3 / 2$ ] The amide $02=\mathrm{C} 2$ groups aren't hydrogen-bonded. These rings are linked into infinite one-dimensional tapes around a two- 
fold screw axis along the $b$ axis. A single tape is composed of single enantiomer and itself is homochiral.

\begin{tabular}{|c|c|c|c|c|}
\hline D-HaA * & D-H & 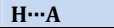 & D $\cdots A$ & 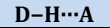 \\
\hline \multicolumn{5}{|l|}{ (rac)-IPrMH } \\
\hline $\mathrm{N} 2-\mathrm{H} \cdots 01^{i i}$ & $0.862(17)$ & $1.970(15)$ & $2.8226(13)$ & $168.9(16)$ \\
\hline \multicolumn{5}{|l|}{ (S)-IPrMH } \\
\hline $\mathrm{N} 1-\mathrm{H} \cdots 01^{i i i}$ & $0.84(3)$ & $2.02(3)$ & $2.841(2)$ & $166(2)$ \\
\hline $\mathrm{N} 2-\mathrm{H} \cdots \mathrm{O} 1^{i v}$ & $0.94(2)$ & $1.89(2)$ & $2.819(2)$ & $169(2)$ \\
\hline
\end{tabular}

(iii) $-x, y+1 / 2,-z+2 ;($ iv $)-x, y-1 / 2,-z+2$.

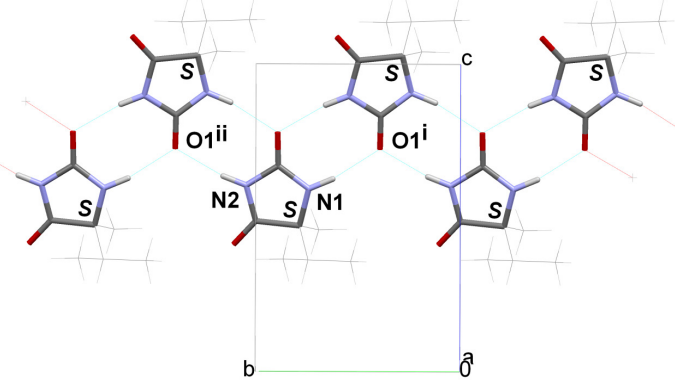

Figure 5. Crystal packing of ( $r a c)$-IPrMH viewed down the $a$ axis, showing the hydrogen-bonded one-dimensional $(S)$-tape running along the $b$ axis. Hydrogen bonds are shown as dashed cyan lines (see Table 4 for details).

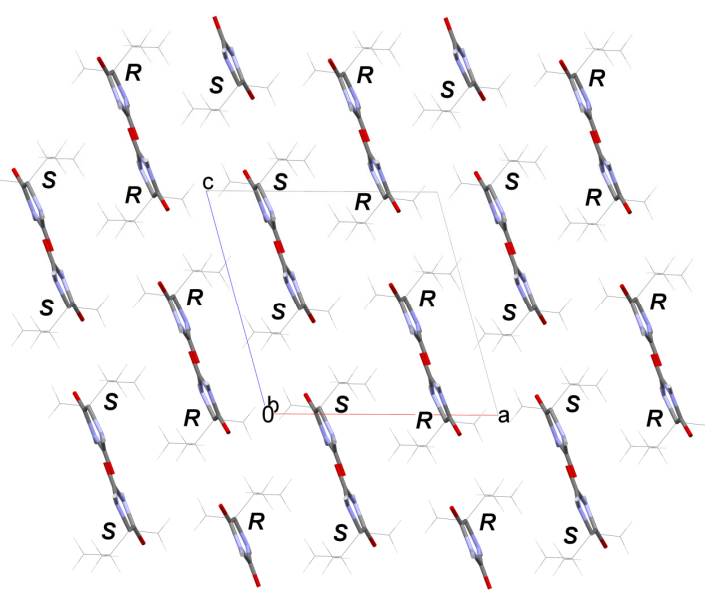

Figure 6. Crystal packing of $(\mathrm{rac})$-IPrMH viewed down the $b$ axis, showing the stacking of $(S)$-tapes and $(R)$-tapes.

As shown in Figure 7 and Table 4, (S)-IPrMH crystal is very similar to $(\mathrm{rac})$-IPrMH crystal in $\mathrm{N}-\mathrm{H} \cdots \mathrm{O}$ hydrogen-bonding

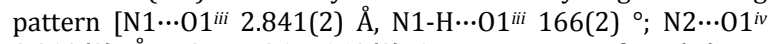
$2.819(2) \AA$, $\mathrm{N} 2-\mathrm{H} \cdots 01^{i v} 169(2){ }^{\circ}$; symmetry codes: (iii) $-x$, $y+1 / 2,-z+2$; (iv) $-x, y-1 / 2,-z+2]$. On the other hand, $(S)$ IPrMH crystal is quite different from ( $r a c)$-IPrMH crystal in the packing mode of the one-dimentional tapes by the hydrogen bonds. As shown in Figure 6, (rac)-IPrMH crystal is formed by the alternate packing of two different kinds of homochiral tapes, represented as $(S)$-tapes and $(R)$-tapes. $(S)$-IPrMH crystal is formed by the packing of only $(S)$-tapes (Figure 8).

\section{Conclusion}

The racemic IPrMH exhibits lower melting temperature than the pure enantiomer by $25^{\circ} \mathrm{C}$. The solid state IR spectrum of the racemic IPrMH is identical with that of the pure enantiomer. These experimental results suggest the formation of conglomerate crystals. Nevertheless, the racemic IPrMH doesn't crystallize as a conglomerate but as a racemic compound. In the racemic and the enantiomeric crystals, the molecular geometries and the intermolecular interactions are very similar to each other. In the both cases, the amide $\mathrm{N} 1-\mathrm{H}$ and $\mathrm{N} 2-\mathrm{H}$ of one molecule are hydrogen-bonded to the amide 01=C1 groups of neighboring molecules to form $R_{2}^{2}(8)$ rings, and these rings are linked into infinite one-dimensional tapes. In the racemic crystal, a single tape is composed of single enantiomer and itself is homochiral.

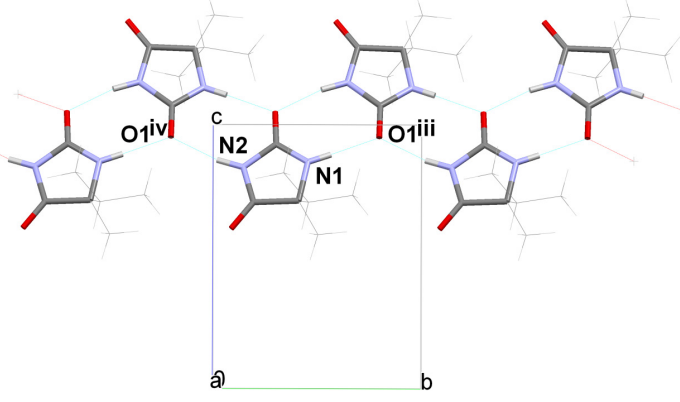

Figure 7. Crystal packing of (S)-IPrMH viewed down the $a$ axis, showing the hydrogen-bonded one-dimensional tape running along the $b$ axis. Hydrogen bonds are shown as dashed cyan lines (see Table 4 for details).

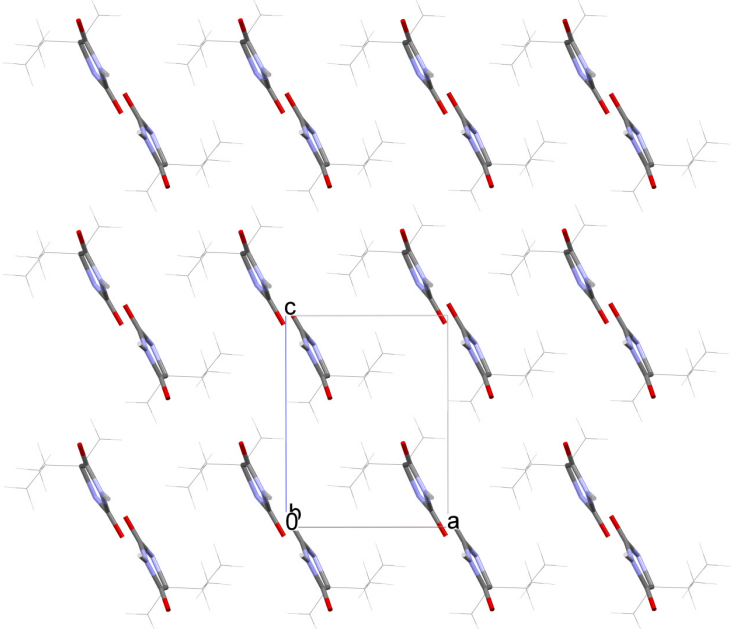

Figure 8. Crystal packing of (S)-IPrMH viewed down the $b$ axis, showing the stacking of $(S)$-tapes.

\section{Supplementary materials}

CCDC-962338 and CCDC-962341 contain the supplementary crystallographic data for this paper. These data can be obtained free of charge via www.ccdc.cam.ac.uk/data request/cif, or by e-mailing data request@ccdc.cam.ac.uk, or by contacting The Cambridge Crystallographic Data Centre, 12 Union Road, Cambridge CB2 1EZ, UK; fax: +44(0)1223-336033.

\section{References}

[1]. Mutschler, E.; Derendorf, H. Drug Actions, Basic Principles and Therapeutic Aspects, Medpharm Scientific Publishers, Stuttgart, 1995. [2]. Knabe, J.; Baldauf, J.; Ahlhem, A. Pharmazie 1997, 52, 912-919.

[3]. Dylag, T.; Zygmunt, M.; Maciag, D.; Handzlik, J.; Bednarski, M.; Filipek, B.; Kiec-Kononowicz, K. Eur. J. Med. Chem. 2004, 39, 1013-1027.

[4]. Opacic, N.; Barbaric, M.; Zorc, B.; Cetina, M.; Nagl, A.; Frkovic, D.; Kralj, M.; Pavelic, K.; Balzarini, J.; Andrei, G.; Snoeck, R.; De Clercq, E.; RaicMalic, S.; Mintas, M. J. Med. Chem. 2005, 48, 475-482.

[5]. Lattmann, E.; Ayuko, W. O.; Kinchinaton, D.; Langley, C. A.; Singh, H.; Karimi, L.; Tisdale, M. J. J. Phar. Pharmacol. 2003, 55, 1259-1265. 
[6]. Carmi, C.; Cavazzoni, A.; Zuliani, V.; Lodola, A.; Bordi, F.; Plazzi, P. V.; Alfieri, R. R.; Petronini, P. G.; Mor, M. Bioorg. Med. Chem. Lett. 2006, 16, 4021-4025.

[7]. Singh, G.; Driever, P. H.; Sander, J. W. Brain 2005, 128, 7-17.

[8]. Kaindl, A. M.; Asimiadou, S.; Manthey, D.; Hagen, M. V.; Turski, L.; Ikonomidou, C. Cell. Mol. Life Sci. 2006, 63, 399-413.

[9]. Tompkins, J. E. J. Med. Chem. 1986, 29, 855-859.

[10]. Takahashi, A.; Matsuoka, H.; Yamada, K.; Uda, Y. Food Chem. Toxicol. 2005, 43, 521-528.

[11]. Al-Madi, S. H.; Al-Obaid, A. M.; El-Subbagh, H. I. Anti-Cancer Drugs 2001, 12, 835-839.

[12]. Shiozaki, M. Carbohyd. Res. 2002, 337, 2077-2088.

[13]. Marton, J.; Enisz, J.; Hosztafi, S.; Timar, T. J. Agric. Food. Chem. 1993, 41, 148-152.

[14]. Jha, S.; Silversides, J. D.; Boyle, R. W.; Archibald, S. J. Cryst. Eng. Comm. 2010, 12, 1730-1739.

[15]. Cruz-Cabeza, A. J.; Schwalbe, C. H. New J. Chem. 2012, 36, 1347-1354.

[16]. Ogawa, T.; Kitoh, S.; Ichitani, M.; Kuwae, A.; Hanai, K.; Kunimoto, K. Anal. Sci. X-ray Struct. Anal. Online 2007, 23, x199-x200.

[17]. Ogawa, T.; Kitoh, S.; Okagawa, M.; Ichitani, M.; Kuwae, A.; Hanai, K.; Kunimoto, K. Anal. Sci. X-ray Struct. Anal. Online 2007, 23, x201-x202.

[18]. Kunimoto, K.; Ichitani, M.; Ogawa, T.; Kitoh, S.; Kuwae, A.; Hanai, K. Spectrosc. Lett. 2009, 42, 73-80.

[19]. Ogawa, T.; Okumura, H.; Honda, M.; Suda, M.; Fujinami, S.; Kuwae, A.; Hanai, K.; Kunimoto, K. Anal. Sci. X-ray Struct. Anal. Online 2009, 25, 91-92.

[20]. Taniguchi, K.; Okumura, H.; Honda, M.; Suda, M.; Fujinami, S.; Kuwae, A.; Hanai, K.; Maeda, S.; Kunimoto, K. Anal. Sci. X-ray Struct. Anal. Online 2009, 25, 93-94.

[21]. Ichitani, M.; Kitoh, S.; Fujinami, S.; Suda, M.; Honda, M.; Kunimoto, K. Acta Cryst. E 2013, 69, o953-0953.

[22]. Ichitani, M.; Kitoh, S.; Tanaka, K.; Fujinami, S.; Suda, M.; Honda, M.; Kuwae, A.; Hanai, K.; Kunimoto, K. Eur. J. Chem. 2013, 4, 350-352.

[23]. Rigaku CrystalClear, Rigaku Corporation, Tokyo, Japan, 2006.

[24]. Rigaku REQAB, Rigaku Corporation, Tokyo, Japan, 1998.

[25]. Burla, M. C.; Caliandro, R.; Camalli, M.; Carrozzini, B.; Cascarano, G. L.; De Caro, L.; Giacovazzo, C.; Polidori, G.; Siliqi, D.; Spagna, R. J. Appl. Cryst. 2007, 40, 609-613.

[26]. Sheldrick, G. M. Acta Cryst. A 2008, 64, 112-122.

27]. Rigaku CrystalStructure, Rigaku Corporation, Tokyo, Japan, 2010.

[28]. Wang, Z. D.; Sheikh, S. O.; Zhang, Y. Molecules 2006, 11, 739-750.

[29]. Farrugia, L. J. J. Appl. Cryst. 2012, 45, 849-854.

[30]. Macrae, C. F.; Edgington, P. R.; McCabe, P.; Pidcock, E.; Shields, G. P.; Taylor, R.; Towler, M.; van de Streek, J. J. Appl. Cryst. 2006, 39, 453457.

[31]. Mitchell, A. G. J. Pharm. Pharmaceut. Sci. 1998, 1, 8-12.

[32]. Wilhoit, R. C.; Chan, J.; Hall, K. R. J. Phys. Chem. Ref. Data 1985, 14, 1175.

[33]. Etter, M. C. Acc. Chem. Res. 1990, 23, 120-126. 